Abstracta Iranica Abstanica

Revue bibliographique pour le domaine irano-aryen

Volume 28 | 2007

Comptes rendus des publications de 2005

\title{
Grammaire de l'ōrmuṛi de Baraki-Barak (Lōgar, Afghanistan). Wiesbaden, Reichert, 2003.
}

\section{Daniel Septfonds}

\section{(2) OpenEdition}

1 Journals

\section{Édition électronique}

URL : http://journals.openedition.org/abstractairanica/10552

DOI : 10.4000/abstractairanica.10552

ISSN : 1961-960X

Éditeur:

CNRS (UMR 7528 Mondes iraniens et indiens), Éditions de l'IFRI

\section{Édition imprimée}

Date de publication : 15 mai 2007

ISSN : 0240-8910

\section{Référence électronique}

Daniel Septfonds, « Grammaire de l'ōrmuṛī de Baraki-Barak (Lōgar, Afghanistan). Wiesbaden, Reichert, 2003. », Abstracta Iranica [En ligne], Volume 28 | 2007, document 34, mis en ligne le 18 septembre 2007, consulté le 25 septembre 2020. URL : http://journals.openedition.org/abstractairanica/10552 ; DOI : https://doi.org/10.4000/abstractairanica.10552

Ce document a été généré automatiquement le 25 septembre 2020.

Tous droits réservés 


\title{
Grammaire de l'ōrmurīi de Baraki- Barak (Lōgar, Afghanistan). Wiesbaden, Reichert, 2003.
}

\author{
Daniel Septfonds
}

1 En 1959 l'A. « redécouvre » l'ōrmuṛī que l'on croyait éteint - depuis le voyage effectué par E. Benveniste en Afghanistan en 1947. Commencent alors ses recherches qui se poursuivront jusqu'en 1971. "L'ōrmuṛi n'est plus parlé, en Afghanistan, qu'en un seul point du Lōgar [...] l'ōrmuṛī est également parlé à Kânigrâm, dans le Wazirestân pakistanais, par un groupe solidement installé ». (p. 15).

2 Cette publication est une version remaniée d'une partie de la thèse soutenue par l'A. en 1975 : Ch. M. Kieffer, Les parlers de la vallée du Lōgar-Wardak (Afghanistan), Etude de dialectologie iranienne, Thèse de doctorat (Sorbonne Nouvelle). [Les textes qui occupaient 150 pages ne sont plus représentés que par quelques spécimens - ils devraient faire l'objet d'une publication à part (p. 12).]

3 Une des qualités de cette étude, et non des moindres, est que l'A. a une approche ethnolinguistique du terrain et reste constamment soucieux de ne pas lisser la complexité de celui-ci.

4 Ce souci trouve son reflet dans une première partie (pp. 1-59) - c'est moi qui divise - à orientation "anthropologique»: "Abréviations, Éléments Bibliographiques, Avantpropos, Généralités ». L'A. parle de l'ōrmuṛī, à plusieurs reprises, comme d'une langue en voie de disparition (pp. 20, 39, 44) ou d'une langue résiduelle (p. 26) : elle serait avec le parāči une des deux langues représentant une branche sud-est des langues iraniennes (p. 30). Il est vrai que, dans les années 60, elle était parlée par moins de cent locuteurs et qu'elle est à n'en pas douter désormais «éteinte ». [Sans jeu de mots: L'appellation ōrmurs est pashtoune et s'entend comme « feu » (ōr) « mort/éteint » (mər ) alors qu'eux-mêmes se dénomment b(a)raki (p. 25).]

5 Sur l'existence de cette « branche » les opinions divergent (p. 17). Bien que l'A. dise être revenu, après la publication de V. A. Efimov (Jazyk ormuri $v$ sinxronnom $i$ istoričeshom osvěčenij, Moskva, 1986), sur cette conception qu'il défendait néanmoins encore en 
1989 (Ch. M. Kieffer, «Le parāči, l'ōrmuṛī et le groupe des langues iraniennes du SudEst », Compendium linguarum iranicarum, Wiesbaden, Dr. Ludwig Reichert Verlag, pp. 445-455), il en renouvelle l'affirmation sous une forme nuancée (p. 18) combinant généalogie et faits de contact. En réalité, plus que de revenir sur sa position, il la nuance et affirme, ça et là, la spécificité d'un groupe du sud-est.

6 Suit une description de l'ōrmuṛī [seconde partie, pp. 60-219] - «Grammaire »- de facture classique: «Phonologie, Nom, Prépositions-Postpositions, Adjectif-Adverbe, Noms de nombre, Pronoms, Démonstratifs, Interrogatifs, Indéfinis, Verbe, Morphosyntaxe ». L'A. nous livre une description toute en finesse de cette langue telle qu'elle était encore parlée il y a une trentaine d'années. Ainsi, pour ne prendre qu'un exemple, on y trouve une présentation fouillée de ce que l'A. appelle les actualisateurs et les quantificateurs (pp. 111-118). Question dont l'analyse, complexe, est d'importance primordiale pour les deux variétés de cette langue.

7 L'A. consacre alors un chapitre [troisième partie, pp. 220-232] au «[Le] Multilinguisme des ōrmurss» (pp. 220-232). Les ōrmurs du Lōgar sont trilingues : "Ils parlent trois langues, la leur, le kâboli et le pashto et si les jeunes ont déjà ou vont bientôt abandonner l'ōrmurịi, c'est tout simplement parce qu'il ne sert plus à rien hors du cercle familial» (p. 232) [déjà en 1975]. Ce chapitre est particulièrement riche et ne saurait être résumé. L'A. y examine l'effet du multilinguisme sur le plan phonétique (pp. 220-223), sur le plan du lexique (pp.223-230) puis sur le plan syntaxique (pp. 230-232), Pour ne prendre que cette dernière question - particulièrement intéressante d'un point de vue typologique et aréal - l'A. y traite de :

8 1. L'«Actualisation de l'objet ». L'ōrmuṛi de Baraki-Barak connaît [dans ma terminologie] un marquage différentiel de l'objet (MDO) de type persan. (A la différence de la variante de Kānigrām qui, elle, n'est pas sous influence persane.)

9 2. La "Construction ergative ». Au passé, la structure actancielle est grosso modo de type ergatif [c'est plus clair à Kānigrām]. On peut cependant saisir comment, à travers les exemples que nous donne l'A., celle-ci aurait pu glisser, à l'image du persan, vers une structure de type accusatif. Aurait pu glisser ... si elle n'avait pas déjà été en voie d'extinction à l'époque des enquêtes.

Ce qui donne encore plus de prix à cette "grammaire»-comme la dénomme modestement son auteur.

L'ouvrage se clôt sur quelques « Spécimens de textes ōrmuṛī » (pp. 233-249).

La présentation de l'ouvrage est, il va sans dire, impeccable.

\section{INDEX}

Thèmes : 2.2. Langues vivantes et dialectes 
AUTEURS

DANIEL SEPTFONDS

INaLCO / Mondes iranien et indien - Paris 